\title{
PENENTUAN RUMUS TINGGI BADAN BERDASARKAN PANJANG JEJAK KAKI PADA ETNIS JAWA
}

\author{
Mardhatillah Marsa ${ }^{a}$, Yudha Nurhantari ${ }^{a}$, Santosa Budiharjo ${ }^{a}$ \\ ${ }^{a)}$ Departemen Ilmu Kedokteran Forensik dan Medikolegal FKKMK UGM Yogyakarta \\ E-mail :adha.marsa@gmail.com
}

\begin{abstract}
Proof of footprints in forensic identification can be used in the determination personal identification, for example the height. Estimated the height is done by measuring the length of footprints. Based on the literature, height was correlates directly with long bones. Footprints are made by the soles of the feet that are part the long bones. The calculation of the height is more accurate using the formula derived from the population concerned so that testing needs to be done on each population. To find out whether there is a correlation between the length of the footprint of a person's height, especially the Javanese ethnic population and determine the estimation formula of height based on the length of the footprint.

The study subjects consisted of 100 men and 100 Javanese ethnic women aged years who were taken by consecutive sampling technique. Measurements were by measuring subject height and footprint imprint then calculated each of the of right and left footprints. The average height of male Javanese ethnic is 172,36 and woman 158,45 cm. The average length of right and left footprints in males is $23,02 \mathrm{~cm}$ and female $22 \mathrm{~cm}$. Pearson correlation test on all subjects had $\mathrm{r}$ value of 0.968 for right footprint and $\mathrm{r} 0.967$ for left footprint. On the male subject has $\mathrm{r}$ 0.908 for right foot print and $\mathrm{r} 0.902$ for left footprint. In the female subject has $\mathrm{r}$ value 0.927 for the right foot print and $\mathrm{r} 0.931$ for the left footprint. There is a relationship between the length of a person's footprint with height and this study earned a formula of height estimation based on the length of the footprint on the Javanese.
\end{abstract}

Keywords: height, footprint, identification, Javanese ethnics 


\section{PENDAHULUAN}

Salah satu bidang penting dalam ilmu kedokteran forensik adalah identifikasi [1]. Identifikasi forensik merupakan upaya yang dilakukan dengan tujuan membantu penyidik untuk menentukan identitas seseorang.

Penentuan identifikasi personal kerap menjadi suatu masalah dalam kasus pidana maupun perdata [2] .

\begin{tabular}{lrr}
\multicolumn{2}{c}{ Identifikasi forensik } & dapat \\
dilakukan dengan menilai & dan \\
mempelajari berbagai bukti & yang \\
tertinggal. Berbagai jenis bukti
\end{tabular}
identifikasi tersebut diantaranya sidik jari, jejak kaki, dan jejak sepatu yang banyak dijumpai dalam suatu kasus kejahatan [3]. Bukti dalam kasus kriminal adalah semua hal yang dijadikan informasi dalam penyelidikan hukum, yang meliputi kesaksian, dokumen, dan benda tangible yang dapat membuktikan atau menyangkal fakta dugaan atau hipotesis. Dengan demikian jejak kaki dapat kita katakan sebagai bukti dalam suatu kasus kriminal karena dapat memperkuat atau menyangkal hipotesis [4] .

Bukti jejak kaki dapat berupa dua dimensi atau tiga dimensi. Bentuk dua dimensi adalah seperti kaki yang menginjak darah lalu menempel pada lantai tempat kejadian perkara, sehingga meninggalkan jejak. Sedangkan bentuk tiga dimensi adalah seperti kaki yang menginjak pasir, tanah atau lumpur [5].

Setelah mengumpulkan bukti, identifikasi forensik selanjutnya dapat dilakukan dengan menganalisa parameter-parameter penting untuk menentukan setiap individu sehingga mempunyai nilai signifikan yang nyata dalam analisa identifikasi forensik. Perkiraan tinggi badan adalah salah satu parameter tersebut. Tinggi badan menjadi salah satu kriteria identifikasi pribadi yang membantu dalam mempersempit proses penyelidikan dan dengan demikian memberikan petunjuk yang berguna dalam penyelidikan [6]. Ahli antropologi pertama yaitu Trotter dan Glesser yang membuat formulasi estimasi untuk memperkirakan tinggi badan dari berbagai tubuh manusia, hal ini yang kemudian mendorong banyak peneliti mengembangkan berbagai formula untuk berbagai populasi di seluruh dunia [7].

Rumusan masalah berdasarkan paparan diatas yaitu apakah terdapat hubungan antara tinggi badan dan panjang jejak kaki serta bagaimana formula atau rumus regresi estimasi tinggi badan berdasarkan panjang jejak kaki?

Tujuan pada penelitian ini adalah untuk menganalisis adanya hubungan antara panjang jejak kaki dengan tinggi badan pada etnis Jawa kemudian menghasilkan formula/rumus estimasi tinggi badan dari panjang jejak kaki tersebut.

\section{METODE PENELITIAN}

Desain penelitian ini adalah observasi analitik dengan pengambilan data secara cross sectional dengan mengkaji hubungan antara panjang jejak kaki dengan tinggi badan untuk memperoleh rumus tinggi badan pada etnis Jawa.

Subjek penelitian terdiri dari individu laki-laki dan perempuan etnis jawa di Yogyakarta yang berusia 21-30 tahun. Pengambilan subjek dilakukan dengan teknik consecutive sampling.

Kriteria inklusi usia pada penelitian ini adalah didasarkan bahwa pada usia 21 tahun pertumbuhan tulang telah berhenti sedangkan batas usia 30 tahun dikarenakan tinggi badan akan mengalami pengurangan sebanyak 1 $\mathrm{mm}$ per tahun setelah manusia mencapai usia 30 tahun [8]. Untuk kriteria inklusi lainnya yaitu subjek merupakan etnis Jawa minimal hingga 
dua generasi diatasnya, sehat fisik dan mental, memiliki tipe telapak kaki normal arch, dan bersedia menandatangani informed consent.

Instrumen penelitian yang digunakan pada penelitian ini berupa formulir data subjek penelitian serta data antropometris. Pada pemeriksaan klinis, alat yang digunakan adalah alat ukur tinggi badan serta kaliper geser untuk mengukur panjang jejak kaki. Untuk pencetakan jejak kaki digunakan metode visible print yang merupakan cetakan kaki dua dimensi menggunakan media kertas HVS 70 gr dan tinta stensile berwarna merah.

Variabel pada penelitian ini adalah variabel bebas berupa panjang jejak kaki dan variabel tergantung berupa tinggi badan.

Subjek penelitian yang memenuhi kriteria inklusi dimintai kesediaannya untuk menyetujui informed consent, mengisi data subjek serta mengikuti penelitian. Subjek penelitian diukur tinggi badan nya sebanyak dua kali. Subjek lalu diambil cetakan jejak kaki nya dengan sebelumnya kedua telapak kaki dilumuri tinta stensile oleh operator secara merata kemudian subjek dengan hampir bersamaan kedua kaki kanan dan kiri nya menginjakkan kertas HVS yang sebelumnya telah direkatkan ke lantai. Pengambilan cetakan jejak kaki juga dilakukan sebanyak dua kali. Cetakan jejak kaki yang telah ada diukur panjang nya yaitu dari titik paling posterior tumit ke titik ujung jari kaki terpanjang. Data panjang jejak kaki dan tinggi badan yang ada kemudian dimasukkan kedalam data antropometris.

Uji diagnostik yang digunakan adalah korelasi Pearson untuk melihat hubungan antara panjang jejak kaki dengan tinggi badan, sedangkan analisis dengan model regresi dilakukan untuk melihat pengaruh antara panjang jejak kaki dengan tinggi badan sehingga diperoleh rumus estimasi tinggi badan berdasarkan panjang jejak kaki pada etnis Jawa.

\section{HASIL DAN PEMBAHASAN}

Pada penelitian ini, subjek penelitian adalah individu laki-laki dan perempuan etnis jawa yang berusia 21-30 tahun dan berasal dari Jawa Tengah serta DI Yogyakarta. Penelitian dilakukan dengan teknik consecutive sampling pada bulan Juni sampai Oktober 2017. Pada periode tersebut didapatkan 200 subjek yang memenuhi kriteria inklusi.

Subjek penelitian ini merupakan mahasiswa FK UGM dan Fak Sastra UNY yang terdiri dari 100 $(50 \%)$ individu berjenis kelamin laki-laki dan $100 \quad(50 \%)$ individu berjenis kelamin perempuan dengan karakteristik usia sebagai berikut :

Tabel 1. Karakteristik usia subjek penelitian

\begin{tabular}{lrr}
\hline & Nilai & \\
\hline Mean & Usia (tahun) & 23,45 \\
Median & 25,5 \\
Minimal & 21 \\
Maksimal & 30 \\
\hline
\end{tabular}

Pada penelitian ini dilakukan analisa deskriptif untuk melihat apakah gambaran karakteristik subjek penelitian sesuai dengan karakteristik etnis Jawa yang merupakan bagian dari ras Melayu Mongoloid, yang didapatkan hasil sebagai berikut : 
Tabel 2. Karakteristik Subjek Penelitian

\begin{tabular}{|c|c|c|c|}
\hline No & Karakteristik & Frekuensi & Persentase $(\%)$ \\
\hline \multirow[t]{3}{*}{1.} & Jenis Kelamin & & \\
\hline & Laki-laki & 100 & 50 \\
\hline & Perempuan & 100 & 50 \\
\hline \multirow[t]{2}{*}{2.} & Warna Rambut & & \\
\hline & Hitam & 200 & 100 \\
\hline \multirow[t]{4}{*}{3.} & Bentuk Rambut & & \\
\hline & Lurus & 85 & 42,5 \\
\hline & Ikal & 80 & 40 \\
\hline & Keriting & 35 & 17,5 \\
\hline \multirow[t]{5}{*}{4.} & Warna Kulit & & \\
\hline & Putih & 14 & 7 \\
\hline & Kuning Langsat & 52 & 26 \\
\hline & Sawo Matang & 113 & 56,5 \\
\hline & Hitam & 21 & 10,5 \\
\hline \multirow[t]{20}{*}{5.} & Daerah Asal & & \\
\hline & Bantul & 21 & 10,5 \\
\hline & Gunung Kidul & 17 & 8,5 \\
\hline & Kulonprogo & 11 & 5,5 \\
\hline & Sleman & 19 & 9,5 \\
\hline & Blora & 8 & 4 \\
\hline & Banjarnegara & 5 & 2,5 \\
\hline & Boyolali & 7 & 3,5 \\
\hline & Cilacap & 14 & 7 \\
\hline & Demak & 9 & 4,5 \\
\hline & Jepara & 4 & 2 \\
\hline & Karanganyar & 8 & 4 \\
\hline & Klaten & 10 & 5 \\
\hline & Solo & 15 & 7.5 \\
\hline & Magelang & 11 & 5,5 \\
\hline & Pati & 11 & 5,5 \\
\hline & Purbalingga & 9 & 4,5 \\
\hline & Semarang & 9 & 4,5 \\
\hline & Sragen & 9 & 4,5 \\
\hline & Wonosobo & 3 & 1,5 \\
\hline
\end{tabular}

Berdasarkan Tabel 2, subjek terbagi rata jumlahnya antara laki-laki dan perempuan. Seluruh subjek memiliki warna rambut hitam, bentuk rambut subjek terbanyak lurus dan ikal, serta warna kulit subjek didominasi warna sawo matang. Pada penelitian ini, subjek tersebar dari berbagai daerah di Jawa Tengah dan Daerah Istimewa Yogyakarta dengan daerah Bantul merupakan daerah asal

Mardhatillah Marsa, Yudha Nurhantari, Santosa Budiharjo subjek terbanyak. Dari hasil analisa terlihat bahwa karakteristik yang sebagian besar muncul pada subjek dinilai mampu mewakili karakteristik etnis Jawa. 
Tabel 3. Nilai Tinggi Badan dan Panjang Jejak Kaki Subjek Penelitian

\begin{tabular}{|c|c|c|c|c|}
\hline \multirow[t]{2}{*}{ Variabel } & \multicolumn{2}{|c|}{ Nilai Rentang } & \multirow[t]{2}{*}{ Mean } & \multirow[t]{2}{*}{ SD } \\
\hline & Min & Maks & & \\
\hline $\mathrm{TB}(\mathrm{cm})$ & 152,10 & 180,30 & 165,4065 & 7,99231 \\
\hline PJKa (cm) & 17,30 & 27,60 & 22,9970 & 2,78357 \\
\hline PJKi (cm) & 17,40 & 27,80 & 23,0215 & 2,77467 \\
\hline
\end{tabular}

Ket $:$ TB=Tinggi Badan, PJKa=Panjang Jejak Kaki Kanan, PJKi=Panjang Jejak Kaki Kiri

Tabel 4. Nilai Tinggi Badan dan Panjang Jejak Kaki berdasarkan Jenis Kelamin

\begin{tabular}{lllllllll}
\hline Variabel & \multicolumn{4}{c}{ Laki-laki } & \multicolumn{5}{c}{ Perempuan } \\
\cline { 2 - 3 } & \multicolumn{2}{c}{ Nilai Rentang } & Mean & SD & \multicolumn{2}{c}{ Nilai Rentang } & Mean & SD \\
\cline { 2 - 3 } & \multicolumn{1}{c}{ Min } & Maks & & & Min & Maks & & \\
\hline TB & 165,80 & 180,30 & 172,36 & 3,9763 & 152,10 & 166,10 & 158,45 & 3,853 \\
PJKa & 17,60 & 27,60 & 23,026 & 2,7835 & 17,30 & 27,40 & 22,099 & 2,777 \\
PJKi & 17,50 & 27,80 & 23,021 & 2,7746 & 17,40 & 27,50 & 22,011 & 2,783 \\
& & & & & & & & \\
\hline
\end{tabular}

Ket : TB=Tinggi Badan, PJKa=Panjang Jejak Kaki Kanan, PJKi=Panjang Jejak Kaki Kiri

Penilaian panjang jejak kaki berdasarkan jenis kelamin pada penelitian ini memperlihatkan bahwa rata-rata panjang jejak kaki kanan dan kiri pada laki-laki lebih besar daripada rata-rata panjang jejak kaki kanan dan kiri pada perempuan. Nilai rata-rata panjang jejak kaki kanan pada seluruh subjek lebih kecil daripada rata-rata panjang jejak kaki kiri, yaitu 22,99 cm untuk jejak kaki kanan dan 23,02 cm untuk jejak kaki kiri.
Tinggi badan pada subjek dapat dilihat pada penelitian ini memiliki nilai rata-rata $165,40 \mathrm{~cm}$ dengan tinggi minimal $152,10 \mathrm{~cm}$ dan tinggi maksimal 180,30 cm. Berdasarkan jenis kelamin didapatkan nilai rata-rata tinggi badan pada laki-laki adalah $172,36 \mathrm{~cm}$ dengan nilai maksimal dan minimal 180,30 $\mathrm{cm}$ dan $165,80 \mathrm{~cm}$ serta rata-rata tinggi badan pada perempuan adalah $158,45 \mathrm{~cm}$ dengan nilai maksimal $166,10 \mathrm{~cm}$ dan minimal $152,10 \mathrm{~cm}$.

Tabel 5. Hasil Uji Korelasi Pearson

\begin{tabular}{ccccccc}
\hline & \multicolumn{2}{c}{ Seluruh Subjek } & \multicolumn{2}{c}{ Laki-laki } & \multicolumn{2}{c}{ Perempuan } \\
\hline & $\mathrm{R}$ & $P$ & $\mathrm{R}$ & $p$ & $\mathrm{R}$ & $p$ \\
\hline PJKa & $+0,968$ & 0,000 & $+0,908$ & 0,000 & $+0,927$ & 0,000 \\
PJKi & $+0,967$ & 0,000 & $+0,902$ & 0,000 & $+0,931$ & 0,000 \\
\hline
\end{tabular}

Berdasarkan Tabel 5 yang merupakan hasil uji korelasi Pearson pada subjek untuk menentukan hubungan antara panjang jejak kaki dan tinggi badan maka didapatkan pada seluruh subjek dan subjek berdasarkan jenis kelamin laki-laki dan perempuan terdapat hubungan positif signifikan sangat kuat antara tinggi badan dengan panjang jejak kaki kanan dan kiri.

Analisis regresi linier sederhana digunakan untuk melihat pengaruh hubungan variabel dependen tinggi badan terhadap masing-masing variabel independen jejak kaki, yaitu jejak kaki kanan dan kiri. Hasil dari analisis regresi tersebut digunakan 
untuk mendapatkan rumus perkiraan

kaki. tinggi badan berdasarkan panjang jejak

Tabel 7. Analisis Regresi Linier Sederhana Jejak Kaki

\begin{tabular}{cccccccccc}
\hline & \multicolumn{3}{c}{ Seluruh Subjek } & \multicolumn{3}{c}{ Laki-laki } & \multicolumn{3}{c}{ Perempuan } \\
\hline & Constanta & B & SE & Constanta & B & SE & Constanta & B & SE \\
\hline JKa & 101,381 & 2,782 & 1,193 & 75,526 & 3,815 & 4,506 & 117,570 & 1,981 & 1,680 \\
JKi & 101,294 & 2,786 & 1,182 & 76,658 & 3,769 & 4,626 & 117,127 & 2,002 & 1,638 \\
\hline
\end{tabular}

Berdasarkan hasil perhitungan rumus regresi linier sederhana sesuai tabel diatas dapat diperoleh rumus estimasi perkiraan tinggi badan pada seluruh subjek dan juga pada subjek laki-laki maupun subjek perempuan. Perkiraan rumus estimasi tinggi badan berdasarkan panjang jejak kaki pada seluruh subjek :

Tinggi badan $=101,381 \mathrm{~cm}+2,782$ (panjang jejak kaki kanan $\mathrm{cm}$ ) $\mathrm{SE}=$ 1,193

Tinggi badan $=101,294 \mathrm{~cm}+2,786$ (panjang jejak kaki kiri $\mathrm{cm}$ ) $\mathrm{SE}=$ 1,182

Perkiraan rumus estimasi tinggi badan berdasarkan panjang jejak kaki pada subjek laki-laki :

Tinggi badan $=75,526 \mathrm{~cm}+3,815$ (panjang jejak kaki kanan $\mathrm{cm}$ ) $\mathrm{SE}=$ 4,506

Tinggi badan $=76,658 \mathrm{~cm}+3,769$ (panjang jejak kaki kiri $\mathrm{cm}$ ) $\mathrm{SE}=$ 4,626

Perkiraan rumus estimasi tinggi badan berdasarkan panjang jejak kaki pada subjek perempuan :

Tinggi badan $=117,570 \mathrm{~cm}+1,981$ (panjang jejak kaki kanan $\mathrm{cm}$ ) $\mathrm{SE}=$ 1,680

Tinggi badan $=117,127 \mathrm{~cm}+2,002$ (panjang jejak kaki kiri $\mathrm{cm}$ ) $\mathrm{SE}=$ 1,638
Pada penelitian ini dapat disimpulkan bahwa identifikasi jejak kaki merupakan salah satu dari beberapa identifikasi yang dapat memperkuat proses penyelidikan terhadap individu. Jejak kaki dapat digunakan untuk mengidentifikasi tinggi badan yakni dari ukuran panjang jejak kaki. Data ini memperlihatkan hasil yang sama dengan penelitian terdahulu dimana banyak studi yang tidak diragukan lagi menunjukkan bahwa terdapat hubungan yang kuat antara panjang jejak kaki terhadap tinggi badan [9],[10].

Perhitungan tinggi badan yang lebih akurat sebaiknya menggunakan rumus yang berasal dari populasi yang bersangkutan [11], sehingga rumus perkiraan tinggi badan berdasarkan jejak kaki yang didapatkan pada penelitian ini sebaiknya hanya digunakan pada populasi etnis Jawa agar mendapatkan hasil yang lebih akurat dan mendekati tinggi badan sebenarnya.

Ada banyak metode pengambilan cetakan jejak kaki lainnya dan perlu penelitian tersendiri terhadap masing-masing metode untuk kemudian dibandingkan apakah memiliki hasil pengukuran yang sama sehingga rumus estimasi perkiraan tinggi badan pada penelitian ini sebaiknya hanya digunakan pada ukuran panjang jejak kaki hasil cetakan yang sama. 


\section{SIMPULAN dan SARAN \\ Simpulan}

Terdapat hubungan bermakna antara panjang jejak kaki kanan dan kiri terhadap tinggi badan pada populasi etnis Jawa. Sehingga dapat ditentukan perkiraan rumus tinggi badan berdasarkan panjang jejak kaki pada etnis Jawa.

\section{Saran}

Perlu dilakukan penelitian lanjutan pada jejak kaki dengan variabel yang berbeda karena begitu banyak nya informasi yang bisa didapatkan dari satu cetakan jejak kaki saja.

\section{UCAPAN TERIMA KASIH}

Segala puji bagi Allah SWT, karena atas perkenan-Nya lah karya tulis ini dapat terselesaikan. Penulis berharap karya tulis ini dapat bermanfaat dalam upaya membantu sejawat dokter forensik dalam proses identifikasi. Pembuatan karya tulis ini tidak lepas dari bantuan banyak pihak, karena itu penulis menghaturkan terima kasih kepada FK UGM yang telah memberikan bantuan dana masyarakat sehingga dapat terlaksananya penelitian ini dan sukarelawan yang telah bersedia mengikuti penelitian ini. Penulis berharap semoga Allah SWT senantiasa mencurahkan rahmat dan hidayah-Nya kepada semua pihak yang telah membantu.

\section{DAFTAR PUSTAKA}

[1]. Amir, A. Identifikasi. Dalam: Rangkaian Ilmu Kedokteran Forensik. Edisi Kedua. Bagian Ilmu Kedokteran Forensik FK-USU. Medan. 2005. Hal 178-203.

[2]. M.H. Ilmu Kedokteran Forensik. Fakultas Kedokteran Universitas Andalas Press. Padang. 2002. Hal $18-19$.

[3].Tang, Y., Srihari, S.N., Kasiviswanathan, H. Similiarity and Clustering of Footwear Prints.
Granular Computing (GrC), 2010 IEEE International Conference. 2010. P 459 - 464.

[4]. Hails, J. Criminal Evidence. $6^{\text {th }}$ ed. Cengage Learning. New York. 2008. P 82 - 87.

[5].National Research Council. Strengthening Forensic Science in The United States: A Path Forward. National Academies Press. Washington DC. 2009.

[6]. Krishan, K. Footwear Impression Evidence. $2^{\text {nd }}$ ed. CRC Press. Boca Raton. 2008.

[7]. Didia, M.S. On Use of Biometrics in Forensic. Forensic Science International. 188. 2009. P 47 49.

[8]. Comas, J. Manual of Physical Anthropology. Charles C Thomas Publisher. Springfield. 1960. P 45 - 46.

[9]. Furqana, M.E. Estimasi tinggi badan dan berat badan berdasarkan jejak kaki tanpa alas kaki (barefoot). Tesis. Universitas Airlangga. Surabaya. 2007.

[10]. Moorthy, T., Mustaqqim, A. Stature Estimation from Footprint Measurements in Indian Tamils. Egyptian Journal of Forensic Science. 4. 2013. P 7 $-16$.

[11]. Pratama, W.G. Perkiraan Tinggi Badan Berdasarkan Panjang Tulang Panjang. Skripsi. Universitas Riau. Riau. 2012. 